\title{
Changes in the prevalence and correlates of menthol cigarette use in the USA, 2004-2014
}

\author{
Andrea C Villanti, ${ }^{1,2}$ Paul D Mowery, ${ }^{3}$ Cristine D Delnevo, $^{4,5}$ Raymond S Niaura, ${ }^{1,2,6}$ \\ David B Abrams, ${ }^{1,2,6}$ Gary A Giovino ${ }^{7}$
}

- Additional material is published online only. To view please visit the journal online (http://dx.doi.org/10.1136/ tobaccocontrol-2016-053329).

${ }^{1}$ The Schroeder Institute for Tobacco Research and Policy Studies at Truth Initiative, Washington, DC, USA ${ }^{2}$ Department of Health, Behavior and Society, The Johns Hopkins Bloomberg School of Public Health,

Baltimore, Maryland, USA ${ }^{3}$ Biostatistics, Inc, Atlanta, Georgia, USA

${ }^{4}$ Center for Tobacco Studies, School of Public Health, Rutgers, the State University, New Brunswick, New Jersey, USA

${ }^{5}$ Cancer Institute of New Jersey, Rutgers, the State University, New Brunswick, New Jersey, USA ${ }^{6}$ Department of Oncology, Georgetown University Medical Center, Lombardi

Comprehensive Cancer Center, Washington, DC, USA ${ }^{7}$ Department of Community Health and Health Behavior, School of Public Health and Health Professions, University at Buffalo, The State University of New York, Buffalo, New York, USA

\section{Correspondence to} Dr Andrea C Villanti, Schroeder Institute for Tobacco Research and Policy at Truth Initiative, 900 G Street NW, Fourth Floor, Washington DC 20001, USA avillanti@truthinitiative.org

Received 20 July 2016 Accepted 9 September 2016 Published Online First 11 October 2016

\section{(1) crossark}

To cite: Villanti $A C$, Mowery PD, Delnevo CD et al. Tob Control 2016;25 ii14-ii20.

\section{ABSTRACT}

Introduction National data from 2004 to 2010 showed that despite decreases in non-menthol cigarette use prevalence, menthol cigarette use prevalence remained constant in adolescents and adults and increased in young adults. The purpose of the current study was to extend these analyses through 2014. Methods We estimated the prevalence of menthol cigarette smoking in the USA during 2004-2014 using annual cross-sectional data on persons aged $\geq 12$ years from the National Survey on Drug Use and Health. Self-reported menthol status for selected brands that were either exclusively menthol or non-menthol were adjusted based on retail sales data. Data were weighted to provide national estimates.

Results Although overall smoking prevalence has decreased, the proportion of past 30-day cigarette smokers using menthol cigarettes was higher (39\%) in 2012-2014 compared to 2008-2010 (35\%). Youth smokers remain the most likely group to use menthol cigarettes compared to all other age groups. Menthol cigarette prevalence has increased in white, Asian and Hispanic smokers since 2010. Menthol cigarette prevalence exceeded non-menthol cigarette prevalence in youth and young adult smokers in 2014. Among smokers, menthol cigarette use was positively correlated with co-use of cigars. Menthol cigarette and smokeless tobacco co-use also increased from 2004 to 2014.

Conclusions The youngest smokers are most likely to use menthol cigarettes. Among smokers, increases in overall menthol cigarette use and menthol cigarette use in whites, Asians and Hispanics since 2010 are of concern. There is tremendous urgency to limit the impact of menthol cigarettes on public health, particularly the health of youth and young adults.

\section{INTRODUCTION}

National data from 2004 to 2010 showed that despite decreases in non-menthol cigarette use prevalence, menthol cigarette use prevalence remained constant in adolescents and adults and increased in young adults. ${ }^{1}$ This was consistent with trends in non-menthol and menthol cigarettes in the USA over this time period. ${ }^{2}$ While population data have shown significant declines in cigarette use among youth ${ }^{3}$ and adults ${ }^{4}$ in recent years, findings from the 2013-2014 wave of the Population Assessment of Tobacco and Health (PATH) Study indicate that $59.5 \%$ of youth smokers report using menthol cigarettes in the past 30 days. ${ }^{5}$

Evidence syntheses highlight greater experimentation with cigarettes and nicotine dependence among youth menthol cigarette smokers compared to non-menthol cigarette smokers. ${ }^{6-8}$ Studies documenting the differential impact of menthol cigarettes (vs non-menthol cigarettes) on subsequent smoking outcomes among youth and young adults highlight the role of menthol cigarettes in facilitating increased smoking and progression to regular smoking in youth and young adults. ${ }^{9} 10$ Recent studies have also documented the high proportion of polytobacco use in youth ${ }^{11}$ and young adults, ${ }^{12} 13$ though few studies have examined the relationship between menthol cigarette use and other tobacco use.

The 2009 Family Smoking Prevention and Tobacco Control Act required the US Food and Drug Administration (FDA) to ban fruit, candy and clove characterising flavours in cigarettes in September 2009 but did not extend that ban to menthol characterising flavours in cigarettes. FDA's recently issued deeming regulations also failed to propose a ban on menthol in cigarettes or other tobacco products. Since then, several countries have passed bans on menthol cigarettes, including the European Union, and many have implementation dates in $2020 .{ }^{14}$ Local action has occurred more quickly with implementation of menthol cigarette sales bans in several Canadian provinces in 2015 and $2016^{14}$ and the city of Chicago's 2014 ban on the sale of flavoured products (including menthol cigarettes) within 500 feet of schools. ${ }^{15}$ The tobacco marketplace continues to evolve and the largest US cigarette manufacturers have renewed efforts to increase menthol's market share in their portfolios. ${ }^{16}{ }^{17}$ The purpose of this study was to extend our trend analyses through 2014, determine whether there were differences in the distribution of menthol cigarette users from 2008-2010 to 2012-2014 and examine correlations between menthol cigarette use and other tobacco product use over time.

\section{METHODS}

\section{National Survey on Drug Use and Health}

The National Survey on Drug Use and Health (NSDUH) is a nationally representative survey that assesses tobacco, alcohol and drug use behaviours in the US civilian, non-institutionalised population. Respondents are aged 12 years and older. NSDUH respondents were selected using a multistage probability sample. Respondents include persons living in households in addition to residents of noninstitutional group quarters, such as college students living in dormitories, civilians residing on military bases and persons living in group homes, shelters and rooming houses. The sample excludes members of the active-duty military and individuals in institutional group quarters. Racial/ethnic minorities and persons aged $12-25$ years were oversampled. 
Cross-sectional surveys were administered annually from 2004 to 2014. Most interviews were conducted in the respondents' homes by trained interviewers. To increase measurement accuracy, drug use questions-including tobacco questionswere administered by audio computer-assisted self-interviews (A-CASI). The overall response rate from 2004 to 2014 ranged from $58.3 \%$ to $70.0 \%$.

\section{Measures}

Current cigarette smoking in the NSDUH was assessed by asking respondents who had ever smoked whether they had smoked part or all of a cigarette in the previous 30 days. Those who responded affirmatively were subsequently asked to report the brand of cigarettes they smoked most often. They were able to select and verify their usual brand from 2 lists with a total of 57 (60 in 2004) brand names that were presented on-screen. Once respondents selected and verified one of the brands on the screen, they were subsequently asked, "Were the $<$ CIGFILL $>$ cigarettes you smoked during the past 30 days menthol?" (note: '<CIGFILL>' was replaced by the computer programme with the name of the brand the respondent had previously reported and verified as having smoked most often). In 2014, $94 \%$ of smokers selected a brand from the lists offered. The remaining 6\% were asked, "Were the cigarettes you smoked during the past 30 days menthol?"

Owing to concerns about misclassification, especially among adolescents, we examined Nielsen market scanner data to classify major brands for which at least $99 \%$ of sales were menthol or non-menthol. Incorporating a method of Hersey et al, ${ }^{18}$ if a respondent reported usually smoking Kool and also reported on the menthol question that the usual brand was nonmenthol, the respondent's response to the menthol variable question was recoded as menthol. A similar adjustment was made for exclusively non-menthol brands.
Analyses used imputed values for age, gender, race and income available in the data sets. To aid comparison with our previous analyses, ${ }^{1}$ age was categorised as $12-15,16-17,18-$ $21,22-25,26-34$ and 35 years and older. For estimating trends in menthol prevalence over time, age categories were collapsed into three groups: $12-17,18-25$ and 26 years and older. Race/ethnicity was grouped into Hispanic, non-Hispanic white, non-Hispanic black, non-Hispanic Asian, non-Hispanic more than one race and non-Hispanic other. Total family income was separated into three groups: <US\$10 000-US $\$ 29999$, US\$30 000-\$74 999 and US\$75000 or more. Number of days smoked per month among past 30-day smokers was categorised as 1-5, 6-29 and 30 days. Past 30-day cigar use was ascertained by the question: "During the past 30 days, that is, since [DATEFILL], on how many days did you smoke part or all of a cigar?" Past 30-day use of snuff was measured by the item: "During the past 30 days, that is, since [DATEFILL], on how many days did you use snuff?" Similar item wording was used to measure past 30-day use of chewing tobacco: "During the past 30 days, that is, since [DATEFILL], on how many days did you use chewing tobacco?" We combined use of snuff and/or chewing tobacco into one variable measuring past 30-day use of smokeless tobacco. Data were missing for fewer than $2 \%$ on tobacco use items across all NSDUH waves.

\section{Statistical analyses}

Three types of analyses were carried out. For assessing changes in use of menthol cigarettes between 2008-2010 and 20122014, we duplicated table 1 in Giovino et al.$^{1}$ For this phase of the analysis, NSDUH cross-sectional surveys administered annually from 2008 to 2010 were combined for analysis, as were annual surveys conducted from 2012 to 2014. Brand choices for 2008-2010 respondents were adjusted for 100\% menthol based on 2012-2014 sales data. This provided comparisons

Table 1 Prevalence (\%) of menthol cigarette use among past 30-day smokers, by age and gender, race/ethnicity, household income and the number of days smoked/month in the USA, 2008-2010 and 2012-2014

\begin{tabular}{|c|c|c|c|c|c|c|c|c|c|c|c|c|}
\hline & \multicolumn{6}{|c|}{$2008-2010$} & \multicolumn{6}{|c|}{$2012-2014$} \\
\hline & All Ages & $12-17$ & $18-25$ & $26-34$ & $35-49$ & $50+$ & All Ages & $12-17$ & $18-25$ & $26-34$ & $35-49$ & $50+$ \\
\hline Overall & 34.7 & 52.5 & 43.6 & 34.6 & 30.3 & 30.6 & 38.8 & 53.9 & 50.0 & 43.9 & 32.3 & 32.9 \\
\hline \multicolumn{13}{|l|}{ Gender } \\
\hline Male & 30.9 & 49.8 & 40.6 & 32.5 & 24.9 & 25.6 & 34.8 & 50.8 & 45.9 & 39.8 & 29.2 & 26.7 \\
\hline Female & 39.1 & 55.5 & 47.4 & 37.3 & 36.3 & 35.7 & 43.5 & 57.6 & 55.9 & 49.3 & 35.9 & 39.1 \\
\hline \multicolumn{13}{|l|}{ Race/Ethnicity } \\
\hline Non-Hispanic white & 25.6 & 49.5 & 36.1 & 23.6 & 20.0 & 22.5 & 28.9 & 51.6 & 41.7 & 33.4 & 20.9 & 24.0 \\
\hline Non-Hispanic black & 86.0 & 74.2 & 85.7 & 91.3 & 89.0 & 80.4 & 84.6 & 71.3 & 84.3 & 90.5 & 87.2 & 79.8 \\
\hline Non-Hispanic other & 45.1 & 56.0 & 56.1 & 38.7 & 48.5 & 31.6 & 46.7 & 52.6 & 54.4 & 51.6 & 41.9 & 41.8 \\
\hline Non-Hispanic Asian & 30.3 & 58.5 & 48.1 & 27.0 & 24.9 & 17.0 & 38.0 & 39.5 & 54.3 & 42.5 & 25.2 & 27.4 \\
\hline Non-Hispanic more than one race & 41.1 & 54.8 & 50.2 & 30.4 & 47.5 & 33.7 & 38.1 & 57.4 & 57.5 & 52.5 & 30.0 & 23.7 \\
\hline Hispanic & 37.1 & 53.3 & 45.4 & 40.0 & 31.2 & 26.8 & 46.9 & 56.7 & 57.5 & 51.2 & 41.7 & 33.0 \\
\hline \multicolumn{13}{|l|}{ Household income } \\
\hline$<$ US\$10 000 (including loss)-US\$29999 & 38.6 & 53.1 & 43.8 & 42.4 & 36.7 & 32.1 & 43.7 & 54.3 & 50.8 & 51.0 & 39.2 & 37.0 \\
\hline US\$30 000-US\$74 999 & 33.2 & 53.3 & 43.4 & 32.8 & 27.9 & 30.2 & 37.2 & 57.0 & 49.9 & 42.1 & 30.7 & 30.7 \\
\hline US\$75 000 or more & 30.5 & 50.9 & 43.3 & 24.8 & 25.8 & 28.4 & 32.1 & 48.7 & 48.2 & 33.8 & 24.9 & 28.3 \\
\hline \multicolumn{13}{|l|}{ Number of days smoked per month (days) } \\
\hline $1-5$ & 37.7 & 51.2 & 40.8 & 32.4 & 33.4 & 39.1 & 41.4 & 55.3 & 50.0 & 42.3 & 34.3 & 32.3 \\
\hline $6-29$ & 40.5 & 55.5 & 45.2 & 37.7 & 36.8 & 38.6 & 45.7 & 55.7 & 52.4 & 49.0 & 41.1 & 39.2 \\
\hline 30 & 31.8 & 50.5 & 44.0 & 34.1 & 27.7 & 27.7 & 35.4 & 48.5 & 48.3 & 42.2 & 29.3 & 31.2 \\
\hline
\end{tabular}

Source: National Survey on Drug Use and Health. Self-reported menthol status was adjusted if necessary using retail checkout scanner data. Sample size=35 320 .

Bolded percentages indicate statistically significant change from 2008-2010 to 2012-2014 ( $<<0.05$ ). 
between time periods in the prevalence of use of menthol cigarettes. Multivariable logistic models were used to estimate odds ratios (ORs) of menthol cigarette use among past 30-day cigarette smokers, adjusted for age, gender, race/ethnicity, income and number of days smoked; listwise deletion was used to handle respondents with item-level missing data.

Next, we estimated time trends in the use prevalence of menthol and non-menthol cigarettes. Annual prevalence estimates for the use of each type of cigarette were calculated for 2004 to 2014. Regression lines were fitted to the prevalence estimates using piecewise linear regression ${ }^{19}$ in which the dependent variable was the annual prevalence estimates. Differences in the variances of the annual prevalence estimates were accounted for using weighted regression. Separate lines were fitted for menthol and non-menthol prevalence by age $(12-17,18-25$ and 26 years and older). An inflexion point was included that allowed the slopes of the lines to change at year 2010 based on visual examination of the raw data, the last year of our previous analyses and the first full year in which other flavoured cigarettes were no longer on the market. Statistical tests were carried out to assess differences in the slopes of menthol and non-menthol regression lines and, within each type of cigarette, differences in slopes between two time periods: 2004-2010 and 2010-2014.

The third analysis investigated the use of cigars and smokeless tobacco among past 30-day cigarette smokers. Prevalence estimates for past 30-day cigar and smokeless tobacco use were compared for past 30-day menthol and non-menthol cigarette smokers by gender and age. Multivariable logistic models were used to estimate ORs for cigar and smokeless tobacco use between menthol and non-menthol cigarette smokers, adjusted for gender and age. For this analysis, NSDUH annual surveys were combined into three time periods: 2004-2007, 20082011 and 2012-2014. Changes over time in the odds of smoking cigars or using smokeless tobacco for menthol cigarette smokers compared with non-menthol cigarette smokers were also assessed. The top brands of cigars and smokeless used by menthol and non-menthol cigarette smokers were identified.

SAS V.9.4 was used for all analyses. The SAS survey procedures took into account NSDUH's complex survey design. Survey weights were used to adjust for different probabilities of selection and for non-response, producing estimates representative of the US population.

\section{RESULTS \\ Change in prevalence of use of menthol cigarettes between 2008-2010 and 2012-2014}

Table 1 compares the prevalence of use of menthol cigarettes among past 30-day smokers between two time periods: 2008-2010 and 2012-2014. Overall, the percentage of menthol cigarette smokers increased 4.1 percentage points between 2008-2010 and 2012-2014. Menthol prevalence increased for all age groups. The largest increase $(9.3$ percentage points) occurred among smokers aged 26-34 years. Youth smokers aged 12-17 years were more likely to use menthol cigarettes than smokers in any other age group in both time periods. This was true for male and female smokers.

By race, black smokers continued to smoke menthol cigarettes at higher rates than smokers of any other race. However, from 2008-2010 to 2012-2014, the prevalence of menthol cigarette use in black smokers declined 1.4 percentage points. This decline in menthol use occurred among black smokers of all ages, ranging from 0.6 percentage points among those ages 50 years and older to 2.9 percentage points among those who were 12-17 years old. In comparison to black smokers, white, Hispanic, Asian and non-Hispanic other races increased use of menthol cigarettes. The largest increase was found among Hispanic smokers. Overall, between 2008-2010 and 20122014 the percentage of Hispanic smokers using menthol cigarettes rose 9.8 percentage points. The next largest increase was found for Asian smokers for which the menthol prevalence increased 7.7 percentage points. White smokers also increased the use of menthol cigarettes by 3.4 percentage points between 2008-2010 and 2012-2014. The largest increase was found among white smokers aged 26-34 years where the menthol percentage increased 9.8 percentage points.

\section{Multivariable analyses}

Online supplementary table S1 presents the adjusted odds of menthol cigarette use among past 30-day smokers. Consistent with our earlier analyses, the odds of menthol cigarette use are at least three times higher among the youngest smokers (ages 12-15 and 16-17) compared to smokers aged 35 and above. Female and black smokers remained significantly more likely to smoke menthol cigarettes than male and white smokers, respectively. Higher use of menthol cigarette use in women held for blacks and whites when examined separately, with the female/ male difference in menthol prevalence being more pronounced for whites $(\mathrm{OR}=1.8 ; \mathrm{p}<0.01)$ than for blacks $(\mathrm{OR}=1.4$; $\mathrm{p}<0.05$; see online supplementary table $\mathrm{S} 2$ ). There were no differences in the odds of menthol cigarette use among smokers by income, but menthol cigarette smokers were significantly less likely to smoke infrequently (1-5 days per month) than nonmenthol cigarette smokers $(\mathrm{OR}=0.90 ; \mathrm{p}<0.05)$.

\section{Trends in the prevalence of use of menthol compared with non-menthol cigarette use 2004-2014}

Figure $1 \mathrm{~A}-\mathrm{C}$ and tables 2 and 3 show estimated time trends in the prevalence of using menthol and non-menthol cigarettes in the full sample from 2004 to 2014 using piecewise linear regression. Two straight lines with intersection at year 2010 were fitted to each time series for menthol and non-menthol cigarette prevalence. Separate lines were estimated for each age group. Note that the denominator here is all individuals in the relevant age groups, not just cigarette smokers. The fit of the piecewise linear regression models was adequate for menthol and nonmenthol trends in all three age groups. Non-menthol prevalence decreased over time for all three age groups and both time periods. The non-menthol prevalence slope decreased most quickly among 18-25 year-olds in the 2004-2010 time period. Menthol prevalence increased among 18-25 year-olds in the first time period $(0.5$ percentage points per year; $\mathrm{p}<0.01)$ and among persons aged 26 years and older in the second time period $(0.1$ percentage points per year; $\mathrm{p}<0.05)$.

In $2004,4.9 \%$ of youth smoked menthol cigarettes and this prevalence declined to $2.5 \%$ in 2014 (figure $1 \mathrm{~A}$ ). The rate of decline was significantly greater after $2010(\mathrm{p}<0.01$; table 2). Similarly, non-menthol smoking declined among youth, from $6.3 \%$ in 2004 to $2.2 \%$ in 2014 . The slopes of the non-menthol lines were not significantly different between 2004-2010 and 2010-2014. The slopes of the non-menthol and menthol lines were significantly different during 2004-2010 (table 3; $\mathrm{p}<0.01)$. After 2010, the menthol and non-menthol prevalence lines declined at about the same rates $(p=0.08)$. By 2014, smoking rates among youth were low and about the same for menthol and non-menthol cigarette smoking.

Among young adults aged 18-25 years, non-menthol smoking prevalence declined over the study period, from $26.9 \%$ in 2004 


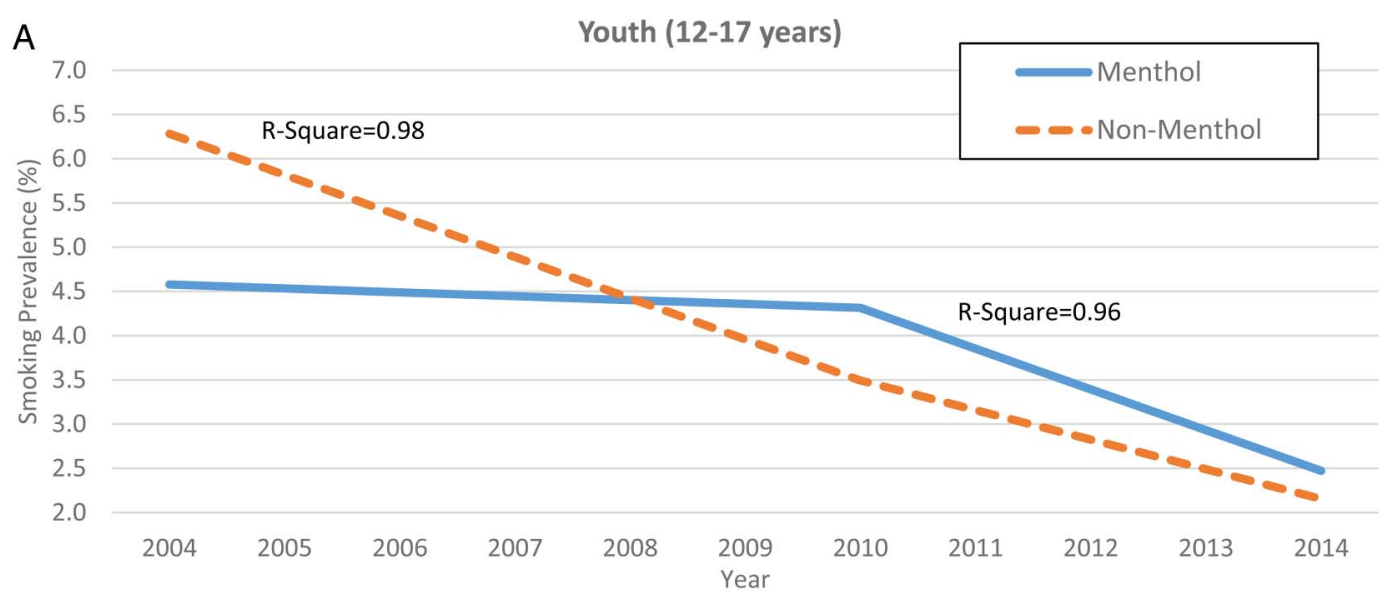

B

Young adults (18-25 years)

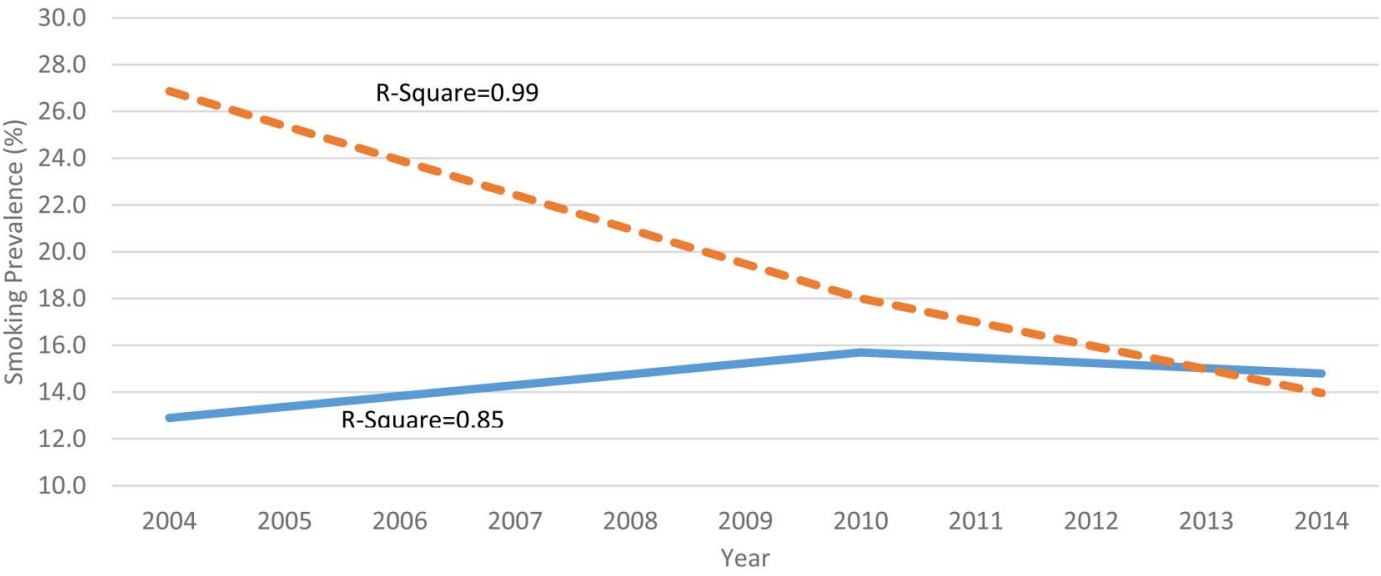

C

Adults aged $26+$ years

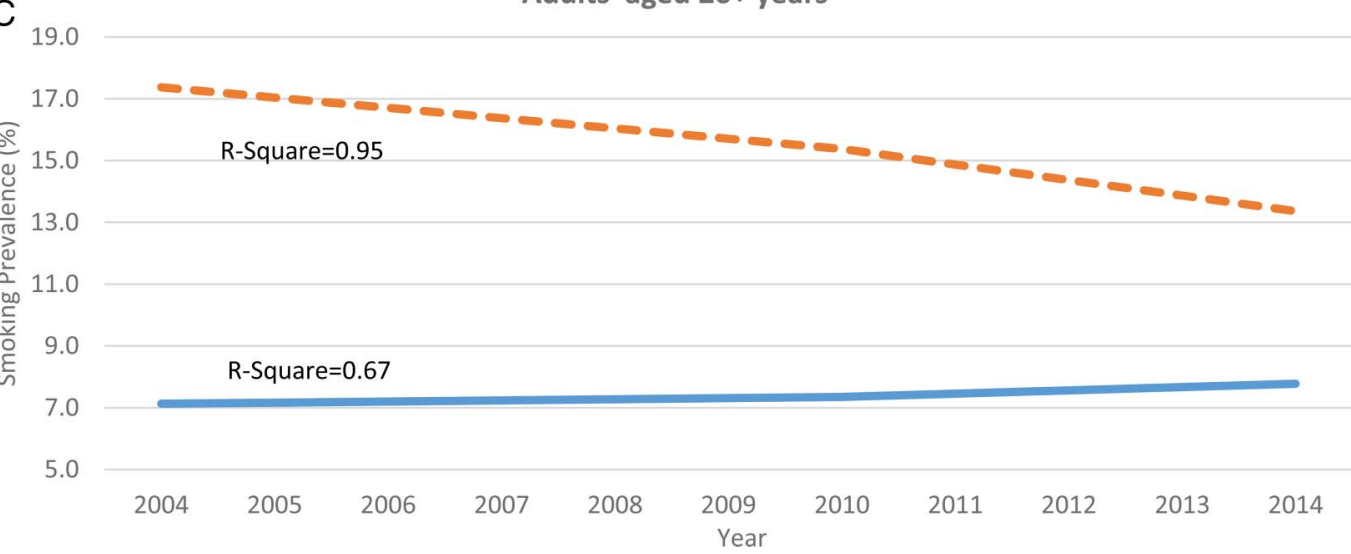

Figure 1 Trends in the prevalence of menthol and non-menthol cigarette smoking (\%) by age in the US population, National Survey on Drug Use and Health, 2004-2014.

to $14.0 \%$ in 2014 (figure 1B). From 2004 to 2010 , the rate of decline was about 1.5 percentage points per year. After 2010, the decline lessened to about 1 percentage point per year. The rates of decline were statistically significant for both time periods $(\mathrm{p}<0.01)$, and the change in slopes at 2010 was statistically significant (table $2 ; \mathrm{p}<0.05$ ). Menthol smoking prevalence among persons aged 18-25 years increased at a rate of about 0.5 percentage points per year during 2004-2010. After 2010, menthol prevalence declined at about 0.2 percentage points per year. The change in slopes across the two time points was statistically significant $(p<0.01)$. The slopes of the non-menthol and menthol lines were significantly different during 2004-2010 (Table 3; $\mathrm{p}<0.01)$, and they were significantly different after 2010 $(p<0.01)$. Although menthol prevalence at the beginning of the time series was lower than non-menthol prevalence, by 2014, menthol prevalence was higher.

Among adults aged 26 and older, menthol prevalence was constant during 2004-2010 and increased slowly (slope $=0.1$ percentage points per year; $\mathrm{p}<0.05$ ) after 2010 (figure 1C). Non-menthol prevalence decreased over the entire study period though the non-menthol slopes were not significantly different between time periods (table 2). The slopes of the non-menthol 
Table 2 Estimated trends* in the prevalence of cigarette smoking by type of cigarette and age, 2004-2014

\begin{tabular}{|c|c|c|c|c|c|c|c|c|}
\hline & \multirow{2}{*}{\multicolumn{3}{|c|}{ Prevalence $(\%) \dagger$}} & \multicolumn{4}{|c|}{ Estimated slopes } & \multirow{3}{*}{$\begin{array}{l}\text { Test for difference in slopes } \\
2004-2010 \text { vs } 2010-2014 \\
\text { p Value }\end{array}$} \\
\hline & & & & \multicolumn{2}{|c|}{ 2004-2010 } & \multicolumn{2}{|c|}{ 2010-2014 } & \\
\hline & 2004 & 2010 & 2014 & Slope & $\mathrm{p}$ Value & Slope & p Value & \\
\hline \multicolumn{9}{|l|}{$12-17$ years } \\
\hline Menthol & 4.6 & 4.3 & 2.5 & -0.04 & 0.28 & -0.46 & $<0.01$ & $<0.01$ \\
\hline Non-menthol & 6.3 & 3.5 & 2.2 & -0.46 & $<0.01$ & -0.33 & $<0.01$ & 0.13 \\
\hline \multicolumn{9}{|l|}{$18-25$ years } \\
\hline Menthol & 12.9 & 15.7 & 14.8 & 0.47 & $<0.01$ & -0.23 & 0.13 & $<0.01$ \\
\hline Non-menthol & 26.9 & 18.0 & 14.0 & -1.48 & $<0.01$ & -1.01 & $<0.01$ & $<0.05$ \\
\hline \multicolumn{9}{|l|}{$26+$ years } \\
\hline Menthol & 7.1 & 7.3 & 7.8 & 0.04 & 0.28 & 0.11 & $<0.05$ & 0.34 \\
\hline Non-menthol & 17.4 & 15.4 & 13.4 & -0.33 & $<0.01$ & -0.50 & $<0.01$ & 0.26 \\
\hline
\end{tabular}

*Time trends estimated using piecewise linear regression with one inflexion point at year 2010.

tPrevalence estimates are predicted from model.

¥Slopes measure the percentage point change in prevalence per year. Bolded slopes indicate statistically significant change between 2004 and 2010 and $2010-2014$ ( $<<0.05$ ).

and menthol lines were significantly different during 20042010 and after 2010 (table 3; both $\mathrm{p}<0.01$ ).

\section{Past 30-day use of cigars and smokeless tobacco among smokers of menthol cigarettes}

Past 30-day use of cigars varied by menthol cigarette use status (table 4). Cigars included big cigars, cigarillos and little cigars, flavoured and non-flavoured. In order to assess changes over time, the total time series was separated into three periods: 2004-2007, 2008-2011 and 2012-2014. Over all three time periods, the prevalence of cigar use among menthol cigarette users remained approximately the same. However, menthol cigarette smokers were more likely to use cigars than non-menthol cigarette smokers. In 2012-2014, 12.9\% of menthol cigarette smokers used cigars compared with $10.6 \%$ of non-menthol cigarette smokers. This difference was statistically significant for all three time periods. Higher cigar prevalence was seen for male and female menthol cigarette smokers compared to non-menthol cigarette smokers. Online supplementary table S3 shows the cigar brand smoked most often by past 30-day cigar users, by cigarette menthol smoking. Black \& Mild cigars were the most highly used among co-users of cigars and cigarettes, with higher prevalence of use among menthol cigarette smokers than non-menthol cigarette smokers across all time periods. In 2012-2014, 43.6\% of menthol cigarette smokers who also used cigars preferred Black \& Mild compared to $30.4 \%$ of non-menthol cigarette smokers.

Over all three time periods, use of smokeless tobacco increased from $3.3 \%$ to $5.0 \%$ in past 30 -day menthol cigarette smokers and from $6.0 \%$ to $6.5 \%$ in past 30-day non-menthol cigarettes smokers (table 4). While the odds of using smokeless tobacco remained lower among menthol compared to nonmenthol cigarette smokers over time, the prevalence of smokeless use among menthol cigarette smokers approached that seen in non-menthol cigarette smokers in the 2012-2014 period $(\mathrm{OR}=0.8)$ compared to the earlier time points $(\mathrm{OR}=0.5$ in 2004-2007 and OR=0.6 in 2008-2011). The higher smokeless tobacco prevalence among non-menthol cigarette smokers was observed for most age groups. Men who smoked non-menthol cigarettes used smokeless tobacco at higher rates than male menthol cigarette smokers. Approximately $6.2 \%$ of male menthol cigarette smokers used smokeless tobacco between 2004 and 2007. This prevalence increased to $9.4 \%$ in $2012-$ 2014 and was statistically significant $(\mathrm{p}<0.01)$. Among male non-menthol cigarette smokers, there was no statistically significant increase in smokeless use between 2004-2007 and 20122014. Unlike cigars, there was not a consistent pattern of brand preference for smokeless products (see online supplementary table S4). In 2004-2007, Skoal was the top smokeless brand identified by cigarette smokers and menthol cigarette smokers reported a higher prevalence of Skoal use than non-menthol cigarette smokers. In the latter two time periods, Grizzly became the top brand, with relatively equal proportions of menthol and non-menthol cigarette smokers using this brand.

\section{DISCUSSION}

Findings from this study highlight five key points: first, although overall smoking prevalence has decreased, the prevalence of menthol cigarette use among past 30-day cigarette smokers

Table 3 Change in slopes of linear regression lines comparing rates of change in menthol and non-menthol smoking prevalence, by time period* $^{*}$

\begin{tabular}{|c|c|c|c|c|c|}
\hline \multirow[b]{2}{*}{ Age } & & \multicolumn{2}{|l|}{ Slopes } & \multirow{2}{*}{$\frac{\text { Difference in slopes }}{\text { (Non-menthol-menthol) }}$} & \multirow[b]{2}{*}{$\mathrm{p}$ Value for different slopes } \\
\hline & & Menthol & Non-menthol & & \\
\hline $12-17$ & 2004-2010 & -0.04 & -0.46 & -0.42 & $<0.01$ \\
\hline 12-17 & 2010-2014 & -0.46 & -0.33 & 0.13 & 0.08 \\
\hline $18-25$ & 2004-2010 & 0.47 & -1.48 & -1.94 & $<0.01$ \\
\hline $18-25$ & 2010-2014 & -0.23 & -1.01 & -0.79 & $<0.01$ \\
\hline $26+$ & $2004-2010$ & 0.04 & -0.33 & -0.37 & $<0.01$ \\
\hline $26+$ & 2010-2014 & 0.11 & -0.50 & -0.61 & $<0.01$ \\
\hline
\end{tabular}

*Slopes measure the percentage point change in prevalence per year. Bolded $p$ values indicate statistically significant difference between menthol and non-menthol cigarette smoking during the time period noted $(p<0.05)$. 
Table 4 Past 30-day use (\%) of cigars* and smokelesst and non-menthol cigarette smokers, by gender and age, USA, 2004-2014

\begin{tabular}{|c|c|c|c|c|c|c|c|c|c|c|c|c|}
\hline \multicolumn{13}{|l|}{ Cigars* } \\
\hline & \multicolumn{4}{|c|}{ 2004-2007 (N=57 451) } & \multicolumn{4}{|c|}{ 2008-2011 ( $\mathrm{N}=53$ 961) } & \multicolumn{4}{|c|}{$2012-2014(\mathrm{~N}=35296)$} \\
\hline & $\begin{array}{l}\text { Menthol } \\
\text { smoker }\end{array}$ & $\begin{array}{l}\text { Non-menthol } \\
\text { smoker }\end{array}$ & $\begin{array}{l}\text { OR (menthol vs } \\
\text { non-menthol } \ddagger \text { ) }\end{array}$ & $\begin{array}{l}\mathrm{p} \\
\text { Value }\end{array}$ & $\begin{array}{l}\text { Menthol } \\
\text { smoker }\end{array}$ & $\begin{array}{l}\text { Non-menthol } \\
\text { smoker }\end{array}$ & $\begin{array}{l}\text { OR (menthol vs } \\
\text { non-menthol } \neq \text { ) }\end{array}$ & $\begin{array}{l}p \\
\text { Value }\end{array}$ & $\begin{array}{l}\text { Menthol } \\
\text { smoker }\end{array}$ & $\begin{array}{l}\text { Non-menthol } \\
\text { smoker }\end{array}$ & $\begin{array}{l}\text { OR (menthol vs } \\
\text { non-menthol }) \text { ) }\end{array}$ & p Value \\
\hline Overall & 13.5 & 11.5 & 1.2 & $<0.01$ & 13.9 & 10.7 & 1.4 & $<0.01$ & 12.9 & 10.6 & 1.3 & $<0.01$ \\
\hline \multicolumn{13}{|l|}{ Gender } \\
\hline Male & 20.6 & 16.7 & 1.3 & $<0.01$ & 20.6 & 15.1 & 1.5 & $<0.01$ & 19.5 & 14.7 & 1.4 & $<0.01$ \\
\hline Female & 7.0 & 4.8 & 1.5 & $<0.01$ & 7.9 & 4.9 & 1.7 & $<0.01$ & 6.8 & 5.0 & 1.4 & $<0.01$ \\
\hline \multicolumn{13}{|l|}{ Age } \\
\hline $12-17$ & 25.1 & 27.8 & 0.9 & $<0.05$ & 26.7 & 26.8 & 1.0 & 0.96 & 22.3 & 25.0 & 0.9 & 0.19 \\
\hline $18-25$ & 23.3 & 20.6 & 1.2 & $<0.01$ & 22.1 & 19.7 & 1.2 & $<0.01$ & 20.1 & 20.1 & 1.0 & 0.99 \\
\hline $26-34$ & 15.1 & 12.0 & 1.3 & $<0.01$ & 15.3 & 10.8 & 1.5 & $<0.01$ & 14.2 & 12.2 & 1.2 & 0.16 \\
\hline $35-49$ & 8.7 & 8.6 & 1.0 & 0.88 & 9.7 & 8.6 & 1.1 & 0.19 & 11.1 & 7.8 & 1.5 & $<0.05$ \\
\hline $50+$ & 5.7 & 5.8 & 1.0 & 0.88 & 6.0 & 6.1 & 1.0 & 0.92 & 5.4 & 7.0 & 0.8 & 0.09 \\
\hline \multicolumn{13}{|c|}{ Smokeless tobaccot } \\
\hline & \multicolumn{4}{|c|}{ 2004-2007 (N=57 514) } & \multicolumn{4}{|c|}{$2008-2011(\mathrm{~N}=54016)$} & \multicolumn{4}{|c|}{$2012-2014(N=35320)$} \\
\hline & $\begin{array}{l}\text { Menthol } \\
\text { Smoker }\end{array}$ & $\begin{array}{l}\text { Non-menthol } \\
\text { smoker }\end{array}$ & $\begin{array}{l}\text { OR (menthol } \\
\text { vs } \\
\text { non-menthol§) }\end{array}$ & $\mathrm{p}$ Value & $\begin{array}{l}\text { Menthol } \\
\text { smoker }\end{array}$ & $\begin{array}{l}\text { Non-menthol } \\
\text { smoker }\end{array}$ & $\begin{array}{l}\text { OR } \\
\text { (menthol vs } \\
\text { non-menthol§) }\end{array}$ & p Value & $\begin{array}{l}\text { Menthol } \\
\text { smoker }\end{array}$ & $\begin{array}{l}\text { Non-menthol } \\
\text { smoker }\end{array}$ & $\begin{array}{l}\text { OR } \\
\text { (menthol vs } \\
\text { non-menthol§) }\end{array}$ & $\mathrm{p}$ Value \\
\hline Overall & 3.3 & 6.0 & 0.5 & 0.01 & 4.4 & 6.7 & 0.6 & $<0.01$ & 5.0 & 6.5 & 0.8 & $<0.01$ \\
\hline \multicolumn{13}{|l|}{ Gender } \\
\hline Male & 6.2 & 10.0 & 0.6 & 0.01 & 8.2 & 11.3 & 0.7 & $<0.01$ & 9.4 & 10.8 & 0.9 & $<0.05$ \\
\hline Female & 0.6 & 0.6 & 0.9 & 0.74 & 0.9 & 0.6 & 1.4 & 0.06 & 0.9 & 0.7 & 1.2 & 0.28 \\
\hline \multicolumn{13}{|l|}{ Age } \\
\hline $12-17$ & 8.2 & 13.8 & 0.6 & $<0.01$ & 12.1 & 15.0 & 0.8 & $<0.01$ & 15.7 & 18.7 & 0.8 & 0.13 \\
\hline $18-25$ & 5.9 & 10.6 & 0.5 & $<0.01$ & 8.1 & 12.4 & 0.6 & $<0.01$ & 8.6 & 13.2 & 0.6 & $<0.01$ \\
\hline $26-34$ & 3.8 & 7.4 & 0.5 & $<0.01$ & 4.2 & 9.2 & 0.4 & $<0.01$ & 5.4 & 10.2 & 0.5 & $<0.01$ \\
\hline $35-49$ & 1.7 & 4.5 & 0.4 & $<0.01$ & 2.5 & 5.5 & 0.4 & $<0.01$ & 3.7 & 5.1 & 0.7 & $<0.05$ \\
\hline $50+$ & 0.9 & 1.9 & 0.5 & 0.07 & 0.9 & 2.1 & 0.4 & $<0.05$ & 1.2 & 1.9 & 0.6 & 0.18 \\
\hline
\end{tabular}

increased significantly from $35 \%$ in $2008-2010$ to $39 \%$ in $2012-$ 2014. Second, youth smokers remain the most likely group to use menthol cigarettes compared to all other age groups and there were significant increases in menthol cigarette use among adults ages $18-25,26-34$ and $35-49$ between the two time periods. Third, while menthol cigarette prevalence has remained constant among black smokers, it has increased in white, Asian and Hispanic smokers. Fourth, dramatic reductions in youth and adult cigarette smoking in recent years have resulted in decreases in menthol cigarette prevalence in youth and young adults, but those declines have not occurred as rapidly as in non-menthol cigarettes. Menthol cigarette prevalence now exceeds nonmenthol cigarette prevalence in youth and young adult smokers. Finally, among past 30-day smokers, menthol cigarette use is positively correlated with co-use of cigars, another harmful combustible product. There has also been an increase in co-use of menthol cigarettes and smokeless tobacco over time. Both are possibly due to the pervasiveness of characterising flavours, including menthol, in these products. ${ }^{20} 21$

Tobacco companies have noted that the menthol segment of the market continues to grow. ${ }^{16}$ The 2015 merger of Lorillard and Reynolds American tobacco companies ${ }^{22}$ has resulted in a strategic push to accelerate the retail impact of the Newport brand, ${ }^{17}$ the top menthol brand in the USA, which has resulted in strong growth of the Newport market share in 2016. Philip
Morris USA also continues to expand their menthol distribution, including new brands such as Marlboro Midnight menthol which were rolled out nationally in November 2015. ${ }^{16}$

This study is limited in several ways. First, the definition of menthol use is based on brand preference. We did not estimate the number of menthol and non-menthol cigarettes smoked during a period of time by each smoker. Rather, we estimate the menthol status of the brand smoked most often. Second, we measured prevalence of use and not incidence of initiation. However, prevalence in young people is largely driven by initiation rather than migration, cessation or death. Third, we did not assess sales data prior to 2008. Nevertheless, brands such as Kool, Newport and Salem have long been classified as menthol brands. ${ }^{23}$ In the latter years, we were unable to recode Newport as menthol due to the increasing prevalence of Newport non-menthol cigarettes in the market. Finally, our data (table 1) indicate that the use of menthol cigarettes among older smokers was less common than among adolescent and young adult smokers. It is impossible to discern with serial cross-sectional data from 2004 to 2014 whether smokers switched away from menthol cigarettes as they aged. The findings might simply indicate higher rates of menthol use among more recent birth cohorts. Cohort surveys with appropriate age groups like the PATH Study will facilitate the study of switching behaviours. 
As in our earlier analyses, ${ }^{1}$ younger age, female gender and black race were significant correlates of menthol cigarette use among past 30-day smokers even after controlling for potential confounders. The age gradient in menthol use persists, such that the youngest smokers are the most likely to use menthol. Increases in overall menthol cigarette use and among white, Asian and Hispanic smokers over a 5 year period are of concern. Similarly, dramatic reductions in cigarette smoking at the population level have been reflected in continued declines in non-menthol cigarette use, but mixed changes in menthol cigarette use in the full sample. The data presented in this study highlight that menthol cigarette prevalence has increased among smokers in recent years and that menthol cigarette use now exceeds non-menthol cigarette use in youth and young adults. Given that cigarettes are the dominant product used in the USA and the most harmful, there is tremendous urgency to enact large-scale efforts at FDA and in state and local policy to limit the impact of menthol cigarettes on public health, particularly the health of youth and young adults.

\section{What this paper adds}

The data presented in this study highlight that among smokers, menthol cigarette prevalence has increased overall since 2010, that age remains inversely associated with menthol cigarette use and that there is co-use of menthol cigarettes with other tobacco products likely to be flavoured (ie, cigars and smokeless tobacco). In 2014, past 30-day menthol cigarette use exceeded non-menthol cigarette use in youth and young adults.

\section{Twitter Follow Cristine Delnevo at @lozzola}

Contributors All authors conceived of the study. ACV and PDM wrote the initial draft of the manuscript. PDM conducted the data analysis. ACV, PDM, CDD, RSN, DBA and GAG contributed to the analysis, interpretation of the data and to the review, revision and approval of the final article.

Funding This study was funded by Truth Initiative.

Competing interests The authors have read and understood Tobacco Control's policy on declaration of interests and declare that they have no competing interests.

Provenance and peer review Not commissioned; externally peer reviewed.

\section{REFERENCES}

1 Giovino GA, Villanti AC, Mowery PD, et al. Differential trends in cigarette smoking in the USA: is menthol slowing progress? Tob Control 2015;24:28-37.

2 Delnevo CD, Villanti AC, Giovino GA. Trends in menthol and non-menthol cigarette consumption in the USA: 2000-2011. Tob Control 2014;23(e2):e154-5.

3 Singh T, Arrazola RA, Corey CG, et al. Tobacco use among middle and high school students-United States, 2011-2015. MMWR Morb Mortal Wkly Rep 2016;65:361-7.
4 Ward BW, Clarke TC, Nugent CN, et al. Early release of selected estimates based on data from the 2015 National Health Interview Survey. US Department of Health and Human Services, Centers for Disease Control and Prevention, National Center for Health Statistics, 2016 [updated May 24]. http://www.cdc.gov/nchs/data/nhis/ earlyrelease/earlyrelease201605.pdf

5 Ambrose BK, Day HR, Rostron B, et al. Flavoured tobacco product use among US youth aged 12-17 years, 2013-2014. JAMA 2015;314:1871-3.

6 Tobacco Products Scientific Advisory Committee. Menthol cigarettes and public health: review of the scientific evidence and recommendations. Rockville (MD): Center for Tobacco Products, Food and Drug Administration, 2011.

7 US Food and Drug Administration. Preliminary scientific evaluation of the possible public health effects of menthol versus nonmenthol cigarettes. Silver Spring (MD): Center for Tobacco Products, Food and Drug Administration, 2013.

8 US Food and Drug Administration. Reference addendum: preliminary scientific evaluation of the possible public health effects of menthol versus nonmenthol cigarettes. Silver Spring (MD): Center for Tobacco Products, Food and Drug Administration, 2013.

9 Delnevo CD, Villanti AC, Wackowski OA, et al. The influence of menthol, e-cigarettes and other tobacco products on young adults' self-reported changes in past year smoking. Tob Control 2016;25:571-4.

10 Nonnemaker J, Hersey J, Homsi G, et al. Initiation with menthol cigarettes and youth smoking uptake. Addiction 2013;108:171-8.

11 Arrazola RA, Neff LJ, Kennedy SM, et al. Tobacco use among middle and high school students-United States, 2013. MMWR Morb Mortal Wkly Rep 2014;63:1021-6.

12 Lee YO, Hebert CJ, Nonnemaker JM, et al. Multiple tobacco product use among adults in the United States: cigarettes, cigars, electronic cigarettes, hookah, smokeless tobacco, and snus. Prev Med 2014:62C:14-19.

13 Fix BV, O'Connor RJ, Vogl L, et al. Patterns and correlates of polytobacco use in the United States over a decade: NSDUH 2002-2011. Addict Behav 2014:39:768-81.

14 Tobacco Control Legal Consortium. How other countries regulate flavoured tobacco products 2015. http://publichealthlawcenter.org/sites/default/files/resources/ tclc-fs-global-flavoured-regs-2015.pdf

15 City of Chicago. City of Chicago Rules: tobacco-flavoured products 2015 [updated December 15]. http://www.cityofchicago.org/content/dam/city/depts/bacp/tobacco/ flavouredtobaccorulesfinal121115.pdf

16 Altria Group's (MO) CEO Marty Barrington on Q4 2015 results-earnings call transcript: seeking alpha; 2016 [updated January 28]. http://seekingalpha.com/ article/3843306-altria-groups-mo-ceo-marty-barrington-q42015-results-earnings-call-transcript

17 Reynolds American. RAI investor day: business update. London, UK: Reynolds American, 2016 [updated May 16]. http://s2.q4cdn.com/129460998/files/doc presentations/2016/RAI-LONDON-2016-FINAL.pdf.

18 Hersey JC, Nonnemaker JM, Homsi G. Menthol cigarettes contribute to the appeal and addiction potential of smoking for youth. Nicotine Tob Res. 2010;12:S136-46.

19 Draper NR, Smith H. Applied regression analysis. New York: John Wiley and Sons, 1998.

20 Delnevo CD, Giovenco DP, Ambrose BK, et al. Preference for flavoured cigar brands among youth, young adults and adults in the USA. Tob Control 2015;24:389-94.

21 Delnevo CD, Wackowski OA, Giovenco DP, et al. Examining market trends in the United States smokeless tobacco use: 2005-2011. Tob Control 2014:23:107-12.

22 Press release: Reynolds American completes acquisition of Lorillard and related divestitures: Reynolds American; 2015 [updated June 15]. http://www. reynoldsamerican.com/About-Us/Press-Releases/Press-Release-Details-/2015/ Reynolds-American-completes-acquisition-of-Lorillard-and-related-divestitures/default. aspx

23 Nielsen AC. Sales data from the 2006 and 2009 Food/Drug/Mass cigarette data base and the 2009 C-Store data. Accessed September 2010. 